\title{
METABOLIC OUTCOME AND PLASMA FATTY ACIDS AFTER ONE-YEAR NUTRITIONAL INTERVENTION IN OBESE CHILDREN CARRIERS OR NON -CARRIERS OF PPAR-Г2 PRO12ALA VARIANT
}

\author{
E. Verduci, G. Radaelli, M. Borzani, M. Giovannini, E. Riva, G. Banderali \\ Department of Pediatrics, San Paolo Hospital, University of Milan, Milan, Italy
}

\begin{abstract}
Aim: To assess whether an association may exist of PPAR- $\gamma 2$ Pro12Ala variant with longitudinal variation in metabolic outcomes and plasma polyunsaturated fatty acids (PUFA) in obese children one-year after nutritional intervention.

Methods: One hundred and nine consecutive normolipidemic obese children (42 girls and 67 boys, age 8-13 yrs,) were analyzed. Body mass index (BMI) z-scores were calculated. Fasting blood samples were evaluated for insulin, glucose, lipid profile and fatty acid (FA) levels at baseline and one-year after nutritionalbehaviour intervention, based on normocaloric balanced diet and physical activity. Insulin resistance was estimated by homeostatic model assessment method (HOMA) and quantitative insulin sensitivity check index (QUICK1). Genomic DNA was obtained from peripheral blood using standard methods, and the Pro12Ala PPAR-g2 variant was detected by DNA sequencing.
\end{abstract}

Results: The frequency of Ala allele was $8 \%$ (Pro/Pro $83.5 \%$, Pro/Ala $16.5 \%$ ). At the end of the intervention children showed decreased BMI z-score (median 0.16; IQR, 0.00-0.3; $\mathrm{P}<0.0001)$ and HOMA $(0,75 ; 0.10$ $1,73 ; \mathrm{P}<0.0001)$ and increased QUICK1 $(0,015 ; 0.005-0,024 ; \mathrm{P}<0.0001)$, but no significant difference was observed between carriers and non-carriers of PPAR- $\gamma 2$ Pro12Ala variant (minimum $\mathrm{P}=0.653$ ). Compared to non-carriers of PPAR- $\gamma 2$ Pro12Ala variant, plasma saturated FA decreased $(\mathrm{P}=0.006)$ while PUFA $(\mathrm{P}=0.014), \mathrm{n}-6$ PUFA $(\mathrm{P}=0.002)$ and $\mathrm{n}-3$ PUFA $(\mathrm{P}=0.047)$ increased more in carriers.

Conclusions: Different response of plasma PUFA to nutritional interventions in obese children may be associated with Pro12Ala variant of the PPAR- $\gamma 2$ gene. 